\title{
Adolescent Cannabis Exposure Alters Opiate Intake and Opioid Limbic Neuronal Populations in Adult Rats
}

\author{
Maria Ellgren', Sabrina M Spano' and Yasmin L Hurd*,' \\ 'Department of Clinical Neuroscience, Karolinska Institutet, Psychiatry Section, Stockholm, Sweden
}

\begin{abstract}
Cannabis use is a hypothesized gateway to subsequent abuse of other drugs such as heroin. We currently assessed whether $\Delta$-9tetrahydrocannabinol (THC) exposure during adolescence modulates opiate reinforcement and opioid neural systems in adulthood. Long-Evan male rats received THC ( $1.5 \mathrm{mg} / \mathrm{kg}$ intraperitoneally (i.p.)) or vehicle every third day during postnatal days (PNDs) $28-49$. Heroin self-administration behavior (fixed ratio- I; 3-h sessions) was studied from young adulthood (PND 57) into full adults (PND I02). THC-pretreated rats showed an upward shift throughout the heroin self-administration acquisition ( $30 \mu \mathrm{g} / \mathrm{kg} /$ infusion) phase, whereas control animals maintained the same pattern once stable intake was obtained. Heightened opiate sensitivity in THC animals was also evidenced by higher heroin consumption during the maintenance phase (30 and $60 \mu \mathrm{g} / \mathrm{kg} /$ infusion) and greater responding for moderate-low heroin doses (dose-response curve: 7.5, 15, 30, 60, and $100 \mu \mathrm{g} / \mathrm{kg} /$ injection). Specific disturbance of the endogenous opioid system was also apparent in the brain of adults with adolescent THC exposure. Striatal preproenkephalin mRNA expression was exclusively increased in the nucleus accumbens (NAc) shell; the relative elevation of preproenkephalin mRNA in the THC rats was maintained even after heroin self-administration. Moreover, $\mu$ opioid receptor ( $\mu \mathrm{OR}$ ) GTP-coupling was potentiated in mesolimbic and nigrostriatal brainstem regions in THC-pretreated animals. $\mu \mathrm{OR}$ function in the NAc shell was specifically correlated to heroin intake. The current findings support the gateway hypothesis demonstrating that adolescence cannabis exposure has an enduring impact on hedonic processing resulting in enhanced opiate intake, possibly as a consequence of alterations in limbic opioid neuronal populations. Neuropsychopharmacology (2007) 32, 607-6 I5. doi:I0.1038/sj.npp. I30I I27; published online 5 July 2006
\end{abstract}

Keywords: cannabinoid; rimonabant; opiate reward; opioid neuropeptide; development

\section{INTRODUCTION}

Marijuana (Cannabis sativa) is the illicit drug most frequently used by teenagers; as much as $15-20 \%$ of 16 year olds in the USA and several European countries report cannabis use during the past month (Hibell et al, 2004; SAMHSA, 2004). The USA population survey also showed that those who started using cannabis at the age of 14 or younger had a higher percentage of present illicit drug abuse or dependence than those starting at an older age (SAMHSA, 2004). The adolescent brain is particularly sensitive to external and internal variables, such as drug exposure, environment, and gonadal hormones, since there are active neural changes in, for example, synapse formation and elimination, brain areas essential for behavioral and cognitive functions (Charmandari et al, 2003; Rice and

\footnotetext{
* Correspondence: Professor Y Hurd, Mount Sinai School of Medicine, Departments of Psychiatry and Pharmacology and Biological Chemistry, One Gustave Levy Place, Box 1215, New York, NY I0029, USA, Tel: + I 212659 1740, Fax: + | 2128310114 ,

E-mail: Yasmin.Hurd@mssm.edu

Received 26 September 2005; revised 24 April 2006; accepted II May 2006

Online publication: 22 May 2006 at http://www.acnp.org/citations/ Npp052206050593/default.pdf
}

Barone, 2000). Consequently, cannabis exposure during the adolescent period may increase the vulnerability to neuropsychiatric and drug abuse disorders. Clinical evidence has confirmed such links. Early-onset cannabis use increases the risk of developing schizophrenia (Arseneault et al, 2002; Fergusson et al, 2003; van Os et al, 2002) as well as a worsen course of the disorder (Green et al, 2004; Veen et al, 2004). Several epidemiological studies report that early regular use of cannabis increases the risk of initiation of the use of other illicit drugs (Agrawal et al, 2004; Fergusson and Horwood, 2000; Lynskey et al, 2003; Yamaguchi and Kandel, 1984), supporting the cannabis gateway hypothesis of cannabis as a steppingstone toward abuse of other drugs. Whether there is or not a causal relationship between cannabis use and the progression to the use of other illicit drugs has been heavily debated over the last decades. Apparent links could be noncausal given that the same characteristics may cause vulnerability to use cannabis as other illicit drugs, that is, genetic predisposition, peer-pressure, drug availability and risk-taking behavior (e.g. Hall and Lynskey, 2005; MacCoun, 1998). However, the associations could also reflect actual neurobiological disturbances to early cannabis exposure that makes individuals more vulnerable to the reinforcing effects of other drugs. The multifactorial confounds of the 'gateway' 
phenomena have made it difficult to make definitive causal links between cannabis use and subsequent abuse of other illicit drugs. One strategy to evaluate directly the relationship of prior cannabis experience with specific drugs independent of cultural, social, and moral factors is the use of experimental animal models.

Converging lines of evidence indicate strong interactions between the cannabinoid and opioid systems. For example, animals lacking the type-1 cannabinoid receptor $\left(\mathrm{CB}_{1}\right.$; mediates the neural actions of cannabinoids) gene do not self-administer heroin (Cossu et al, 2001; Ledent et al, 1999) or develop morphine-induced conditioned place preference. Acute administration of $\Delta$-9-tetrahydrocannabinol (THC; psychoactive component of cannabis) elevates $\beta$-endorphin and enkephalin peptide levels in the ventral tegmental area (VTA; (Solinas et al, 2004b) and nucleus accumbens (NAc; (Navarro et al, 2001), key neuroanatomical substrates for reward (Everitt and Wolf, 2002; Koob, 1992). Moreover, $\mathrm{CB}_{1}$ and $\mu$ opioid receptors ( $\mu \mathrm{ORs}$; mediates heroin's actions) are localized on similar neurons in the striatum and VTA, which modulate reward and motor behaviors (Pickel et al, 2004; Rodriguez et al, 2001).

Owing to the strong interactions between the cannabinoid and opioid systems, the current study was designed to test the hypothesis in an experimental animal model that adults exposed during adolescence to cannabis have altered opioid-related neural functions and enhanced behavioral susceptibility to opiates. Since teenagers normally progress to the use of other illicit drugs as young adults, the effects of adolescent THC exposure were examined starting at a comparable developmental period in rats (postnatal day (PND) 57) and extending into full adulthood.

\section{MATERIALS AND METHODS}

\begin{abstract}
Animals
Male Long-Evan rats (21 days old) were obtained from M\&B Taconic, USA. They were housed in a temperature-controlled environment on a reversed 12-h light/dark cycle (lights off at 1100 hours) with ad libitum access to food and water. The rats were allowed to acclimate in their new environment and were handled daily for 1 week before the start of the experiment. All animal experiments were performed in accordance with the guidelines of The Swedish National Board for Laboratory Animals under a protocol approved by the Ethical Committee of Northern Stockholm, Sweden.
\end{abstract}

\section{Drugs}

THC $(10 \mathrm{mg} / \mathrm{ml}$ in ethanol solution; Sigma-Aldrich, Sweden) was evaporated under nitrogen gas, dissolved in $0.9 \% \mathrm{NaCl}$ with $0.3 \%$ Tween 80 , and administered intraperitoneal (i.p.) in a volume of $2 \mathrm{ml} / \mathrm{kg}$. Heroin $\mathrm{HCl}$ (Apoteket AB, Sweden) was dissolved in $0.9 \% \mathrm{NaCl}$ and administered intravenously at a volume of $85 \mu \mathrm{l} /$ infusion. Rimonabant (also known as SR 141716A; Sanofi-Aventis) was dissolved in $0.9 \% \mathrm{NaCl}$ and administered i.p. in a volume of $2 \mathrm{ml} / \mathrm{kg}$.

\section{Adolescent Cannabis Exposure}

The rats were exposed to THC $(1.5 \mathrm{mg} / \mathrm{kg}$. i.p. $)$ or vehicle $(0.9 \% \mathrm{NaCl}$ with $0.3 \%$ Tween 80$)$ during PNDs $28-49$ to extend beyond the prototypic adolescent period (days 2842 ), which starts around 10 days before puberty and ends a few days after (Spear, 2000), into mid-adolescence (Andersen, 2003). In order to mimic the intermittent use seen in teenagers, the drug was given once every third day; this resulted in a total of eight injections. One week after the last injection, heroin self-administration (outlined below) was initiated in one set of animals and brains were taken in another group of rats for post-mortem studies. The low-moderate dose of $1.5 \mathrm{mg} / \mathrm{kg}$ was chosen since our pilot studies showed that it had no significant effect on locomotor activity and did not induce catalepsy in adolescent animals (data not shown).

\section{Intravenous Heroin Self-Administration}

One day after the last THC $(n=6)$ or vehicle $(n=6)$ injection, intravenous catheters (Brian Fromant, Cambrige, UK) were implanted into the right jugular vein under isoflurane (Isofluran Baxter, Apoteket $\mathrm{AB}$, Sweden) anesthesia. During the first 3 days of recovery, the catheters were flushed with $0.1 \mathrm{ml}$ of a saline solution containing $10 \mathrm{U}$ heparin (Heparin LEO, Apoteket AB, Sweden) and ampicillin $(50 \mathrm{mg} / \mathrm{kg}$; Doctacillin, Apoteket AB, Sweden). During this period, the rats were also given the analgesic carprofen $(0.5 \mathrm{mg} / \mathrm{kg}$ s.c.; Rimadyl vet, Apoteket AB, Sweden). From the fourth day, the catheters were flushed with $0.1 \mathrm{ml}$ of saline containing $30 \mathrm{U}$ heparin. This was also carried out before and after all self-administration sessions. One week after the last THC or vehicle injection, on PND 57, the rats were introduced to the self-administration paradigm during daily $3 \mathrm{~h}$ sessions on a fixed ratio-1 (FR-1) schedule of reinforcement. The self-administration sessions were carried out within the first $6 \mathrm{~h}$ of the dark phase of the light/dark cycle. The self-administration equipment (MED Associates Inc., Vermont, USA) was programmed such that when the active lever was depressed a drug infusion was delivered ( $85 \mu$ l over $5 \mathrm{~s}$ ) and a $10 \mathrm{~s}$ time-out period was initiated where both levers were retracted and a white stimulus light situated above the active lever was turned on; a dim red house light was on during the entire session. Depression of the inactive lever had no programmed consequences, but was recorded by the software (MedPC IV, MED Associates Inc., Vermont, USA). Drug selfadministration was continuous with no drug-free periods during the acquisition and maintenance phases. THC and vehicle-pretreated rats were processed simultaneously throughout all phases of the self-administration procedure. The animals were first trained to self-administer intravenous infusions of $15 \mu \mathrm{g} / \mathrm{kg}$ heroin. After 6 days, the dose of heroin was increased to $30 \mu \mathrm{g} / \mathrm{kg} /$ infusion and the rats received one priming infusion at the start of the following 1-4 sessions, until they started to press on their own. The rats were food-restricted ( $20 \mathrm{~g}$ food pellets/day) during the acquisition phase that continued for 14 days at the $30 \mu \mathrm{g} / \mathrm{kg} /$ infusion dose. Stable self-administration behavior was defined as a minimum of 10 respondings on the active lever and at least a 2:1 ratio in active:inactive lever presses for three consecutive sessions. Following a 3-day maintenance period at $30 \mu \mathrm{g} / \mathrm{kg} /$ infusion FR-1 schedule, a between-session dose-response test was initiated $(30,7.5$, 100,15 , and $60 \mu \mathrm{g} / \mathrm{kg} /$ infusion heroin; one dose per day). 
Subsequently, the rats were kept on a maintenance heroin dose of $60 \mu \mathrm{g} / \mathrm{kg}$ (which reliably maintained heroin intake behavior) FR-1 schedule and the effects of acute pretreatment (20 min before the session start) with the $C_{1}$ antagonist Rimonabant $(0.3,1.0$, and $3.0 \mathrm{mg} / \mathrm{kg}$ i.p.) was evaluated. Finally, heroin-seeking behavior was studied using a paradigm where the number of responses on the active lever were counted but had no programmed consequences; no heroin was delivered or cue light presented during this session. The effect of acute pretreatment with Rimonabant $(3.0 \mathrm{mg} / \mathrm{kg}$ i.p.) on heroin-seeking behavior was also determined. Stable heroin intake behavior was established for at least 3 days prior to all behavioral or pharmacological manipulations. Twenty-four hours after the last heroin self-administration session, rats were killed as described below and brains were processed for postmortem studies.

\section{Post-Mortem Brain Studies}

Brain section preparation. Rats were anesthetized in a $\mathrm{CO}_{2}$ chamber and decapitated. Brains were quickly removed, frozen in isopentane $\left(\approx-30^{\circ} \mathrm{C}\right)$ for $1 \mathrm{~min}$, and stored at $-80^{\circ} \mathrm{C}$ until cutting. Coronal sections $(20 \mu \mathrm{m}$ thick $)$ of the striatum and midbrain were cut in a refrigerated cryostat $\left(-15^{\circ} \mathrm{C}\right.$; Frigocut $2800 \mathrm{E}$, Leica Instruments, Nobloch, Germany) according to Paxinos and Watson Rat Atlas (1997) and mounted onto Superfrost Plus slides (Brain Research Laboratories, Newton, MA, USA). The sections were stored at $-30^{\circ} \mathrm{C}$ until processed as described below.

In situ hybridization. The PENK mRNA probe was complementary to a $333 \mathrm{~kb}$ fragment of the rat PENK cDNA (291-624 bp, GenBank accession number Y07503). The RNA probe was transcribed in the presence of $\left[{ }^{35} \mathrm{~S}\right]$ uridine $5^{\prime}$ ( $\alpha$-thio)triphosphate (specific activity $1000-1500 \mathrm{Ci} / \mathrm{mmol}$; New England Nuclear, Boston, MA, USA). Chemicals used in the hybridization procedure were mainly purchased from Sigma-Aldrich (MO, USA) and enzymes from Invitrogen (CA, USA). The in situ hybridization histochemistry procedure was similar to published protocols (Hurd et al, 2001). Briefly, the labeled probe was applied to the brain sections in a concentration of $2 \times 10^{3}$ c.p.m. $/ \mathrm{mm}^{2}$ of the coverslip area. Two adjacent sections from each subject were studied. Hybridization was carried out overnight at $55^{\circ} \mathrm{C}$ in a humidified chamber. After in situ hybridization, the slides were apposed to $\beta$-max Hyperfilm (Amersham, Bucks, UK) along with ${ }^{14} \mathrm{C}$-standards (American Radiolabelled Chemicals, St Louis, MO, USA).

[ $\left.{ }^{3} \mathrm{H}\right]$-WIN 55,212-2 (cannabinoid receptor) autoradiography. $\left[{ }^{3} \mathrm{H}\right]$-WIN 55,212-2 binding was measured in order to determine potential changes of cannabinoid receptor density in association with the THC pretreatment. Sections were preincubated in $20 \mathrm{mM}$ HEPES buffer with $0.5 \%$ (wt/ vol) bovine serum albumin (BSA; fatty acid-free), $\mathrm{pH} 7.0$ for $20 \mathrm{~min}$ at $30^{\circ} \mathrm{C}$, and then incubated in $1 \mathrm{nM}\left[{ }^{3} \mathrm{H}\right]-$ WIN 55,212-2 [R-(+)-(2,3-dihydro-5-methyl-3-[(4-morpholinyl)methyl]pyrol[1,2,3-de]-1,4-benzoxazinyl)(1-naphthalenyl)methanonemesylate] (Perkin-Elmer, Life Science Inc., Boston, MA) for $80 \mathrm{~min}$ at $30^{\circ} \mathrm{C}$. Nonspecific binding was assessed in the presence of $10 \mu \mathrm{M}$ nonlabeled WIN 55,212-2.
Slides were rinsed four times for $10 \mathrm{~min}$ each in the preincubation buffer at $25^{\circ} \mathrm{C}$ and then twice in cold distilled water. Slides were dried overnight and exposed to $\beta$-max Hyperfilm for 14 days.

$\left[{ }^{3} \mathrm{H}\right]\left(\mathrm{D}-\mathrm{Ala^{2 }}, \mathrm{N}-\mathrm{Me}\right.$-Phe $\mathrm{e}^{4}$ Gly ${ }^{5}$-ol]-enkephalin ([$\left.\left.{ }^{3} \mathrm{H}\right]-\mathrm{DAMGO}\right)$ $(\mu O R)$ autoradiography. $\left[{ }^{3} \mathrm{H}\right]$-DAMGO binding was carried out in order to examine whether THC pretreatment altered $\mu \mathrm{OR}$ density. Slide-mounted brain sections were preincubated at $25^{\circ} \mathrm{C}$ for $15 \mathrm{~min}$ in $50 \mathrm{mM}$ Tris- $\mathrm{HCl}(\mathrm{pH} \mathrm{7.4)}$, $100 \mathrm{mM} \mathrm{NaCl}, 1 \% \mathrm{BSA}$, and briefly washed three times in $50 \mathrm{mM}$ Tris ( $\mathrm{pH}$ 7.4). $\mu \mathrm{OR}$ binding sites were labelled by incubating sections for $1 \mathrm{~h}$ at $25^{\circ} \mathrm{C}$ in the presence of $2 \mathrm{nM}$ $\left[{ }^{3} \mathrm{H}\right]-\mathrm{DAMGO}$ (Perkin-Elmer, Life Science Inc.). Nonspecific binding was defined in the presence of $1 \mu \mathrm{M}$ naloxone. After incubation, slides were rinsed three times for $5 \mathrm{~min}$ each in the ice-cold incubation buffer, dipped in ice cold distilled water, dried overnight, and placed in a $\beta$-Imager (Biospace Mesures, France), which allows direct on-line beta emission quantification.

Agonist-stimulated $\left[{ }^{35} S\right] G T P \gamma S$ autoradiography. WIN 55,212-2- and DAMGO-induced $\left[{ }^{35} \mathrm{~S}\right] \mathrm{GTP} \gamma \mathrm{S}$ stimulation was measured in order to asses whether THC pretreatment altered $\mathrm{CB}_{1}$ and $\mu \mathrm{OR}$ receptor function, respectively. Brain sections were rinsed in binding buffer $(50 \mathrm{mM}$ Tris- $\mathrm{HCl}$, $3 \mathrm{mM} \mathrm{MgCl}_{2}, 0.2 \mathrm{mM}$ EGTA, $100 \mathrm{mM} \mathrm{NaCl}, \mathrm{pH} \mathrm{7.4)}$ at $25^{\circ} \mathrm{C}$ for $10 \mathrm{~min}$, followed by a $15 \mathrm{~min}$ preincubation in binding buffer containing $2 \mathrm{mM}$ guanosine $\mathrm{D}$ phosphate (GDP) at $25^{\circ} \mathrm{C}$. Sections were then incubated in binding buffer with $2 \mathrm{mM}$ GDP, $100 \mu \mathrm{M}$ DTT, $0.04 \mathrm{nM}\left[{ }^{35} \mathrm{~S}\right] \mathrm{GTP} \gamma \mathrm{S}$ (specific activity $1099 \mathrm{Ci} / \mathrm{mmol}$; Amersham Biosciences, England, $\mathrm{UK})$ and appropriate agonists at $25^{\circ} \mathrm{C}$ for $2 \mathrm{~h}$. Agonists used were as follows: $3 \mu \mathrm{M}$ DAMGO (Sigma-Aldrich, MO, USA) and $10 \mu \mathrm{M}$ WIN 55,212-2 (Sigma-Aldrich, MO, USA). Incubation solutions with WIN 55,212-2 contained $0.5 \%$ (wt/vol) BSA (fatty acid-free). Nonspecific binding was determined in the absence of the agonist and in the presence of $10 \mu \mathrm{M}$ unlabeled GTP $\gamma \mathrm{S}$. After incubation, the slides were rinsed twice $(2 \mathrm{~min})$, in cold Tris buffer $(50 \mathrm{mM}$ Tris- $\mathrm{HCl}, \mathrm{pH}=7.4$ ) and subsequently in cold distilled water. The slides were dried overnight and exposed to film for $24 \mathrm{~h}$ along with ${ }^{14} \mathrm{C}$-microscales (Amersham Bucks, UK).

Data analyses. Films images were digitalized into the 256 levels of optical density with a Microtek scanner (SM III, Microtek Europe, Rotterdam, The Netherlands) and quantitation of film autoradiograms was carried out using computer-assisted optical densitometry (NIH Image, version 1.58, Wayne Rasband, NIMH). Densitometric readings were taken of the NAc, dorsal striatum (caudate-putamen), VTA, and substantia nigra in accordance with the Paxinos and Watson Rat Atlas (1997); identification of different brain nuclei was determined from adjacent sections, which were stained with cresyl violet. Values obtained from duplicate brain sections for each subject were averaged. For in situ hybridization experiments, the values were expressed as d.p.m./mg of tissue by reference to the coexposed ${ }^{14} \mathrm{C}$ standard. For receptor autoradiography, specific binding was calculated by subtracting nonspecific binding from total binding in the specific area of interest. Optical densities measured from film receptor autoradiograms were 
transformed into $\mu \mathrm{Ci} / \mathrm{g}$ tissue using a standard curve generated with the ${ }^{3} \mathrm{H}$-standards. The percent agonistinduced stimulation from the $\left[{ }^{35} \mathrm{~S}\right] \mathrm{GTP} \gamma \mathrm{S}$ autoradiography experiments was calculated as (stimulated-basal)/basal $\times$ 100 . Images from the $\beta$-Imager were analyzed directly as c.p.m. $/ \mathrm{mm}^{2}$ using Betavision Analysis (Biospace Mesures).

\section{Statistical Analysis}

Data were analyzed with one- or two-way analysis of variance (ANOVA) with repeated measures, followed by planned comparisons and Bonferroni correction for multiple comparisons when appropriate. Statistical significance was set as $p<0.05$ and trends considered for $p<0.10$.

\section{RESULTS}

Adolescent THC exposure did not affect the body weight of the rats. The THC- and vehicle-exposed rats increased $136.7 \pm 4.2$ and $142.3 \pm 7.5 \mathrm{~g}$ in body weight, respectively, during the 21-day pre-exposure period (no significant group difference; $(\mathrm{F}(1,10)=0.50, p=0.49))$.

\section{Heroin Self-Administration}

Acquisition. None of the rats acquired self-administration at the heroin dose of $15 \mu \mathrm{g} / \mathrm{kg} /$ infusion during the time period studied. When the dose was increased to $30 \mu \mathrm{g} / \mathrm{kg} /$ infusion and in combination with modest autoshaping (one drug prime and food restriction), all animals acquired self-administration behavior. One rat in the vehicle group developed a blocked catheter during the acquisition period and was excluded from the remainder of the study. There was a significant effect of self-administration session $(\mathrm{F}(12,96)=54.94, p<0.000001)$ and pretreatment $\times$ session interaction $(\mathrm{F}(12,96)=8.29, p<0.000001)$ for heroin intake behavior (active lever presses) during the $30 \mu \mathrm{g} / \mathrm{kg} /$ infusion acquisition phase. Vehicle-exposed animals reached stable heroin self-administration behavior at day 6 of acquisition, which was maintained throughout the remainder of the acquisition phase (Figure 1). Although THC pre-exposed animals had met the acquisition criteria at approximately day 7 , a stable intake pattern was not maintained. All THC-pretreated rats continued to shift their heroin intake upward over the course of the acquisition phase stabilizing eventually at approximately 25 total responses as compared to 15 total responses in the control animals by the end of the acquisition phase.

\section{Dose Response}

As illustrated in Figure 2, the between-session doseresponse experiment $(7.5-100 \mu \mathrm{g} / \mathrm{kg} /$ infusion) confirmed a higher response and intake of heroin in THC-exposed rats. Two-way ANOVA with repeated measures showed a significant overall effect of pretreatment $(\mathrm{F}(1,7)=7.10$, $p<0.05)$, dose $\quad(\mathrm{F}(4,28)=35.72, \quad p<0.000001)$, and dose $\times$ pretreatment $(\mathrm{F}(4,28)=0.59, p=0.0174)$. Post hoc planned comparisons revealed that THC-exposed rats had a tendency toward higher intake at $7.5 \mu \mathrm{g} / \mathrm{kg} /$ infusion $(p=0.057)$ and significantly higher intake at $30 \mu \mathrm{g} / \mathrm{kg} /$ infusion $(p<0.01)$ as well as $60 \mu \mathrm{g} / \mathrm{kg} /$ infusion $(p<0.05)$.

Maintenance. During maintenance phases at both 30 and $60 \mu \mathrm{g} / \mathrm{kg} /$ infusion, rats exposed to THC during adolescence had a higher level of responding (Figure 3); there was a significant group difference in total intake over 4 days of stable responding at $30 \mu \mathrm{g} / \mathrm{kg} /$ infusion $(\mathrm{F}(1,9)=5.61$, $p<0.05))$ and $60 \mu \mathrm{g} / \mathrm{kg} /$ infusion $(\mathrm{F}(1,8)=9.26, p<0.05))$.

$C B_{1}$ antagonism. Administration (30 min before the session) of the $\mathrm{CB}_{1}$ antagonist Rimonabant $(0.3,1.0$, and $3.0 \mathrm{mg} / \mathrm{kg}$ i.p.) was carried out to determine acute cannabinoid effects on heroin intake behavior. No difference in heroin selfadministration was observed dependent on the THC pretreatment, but there was a significant overall dose effect

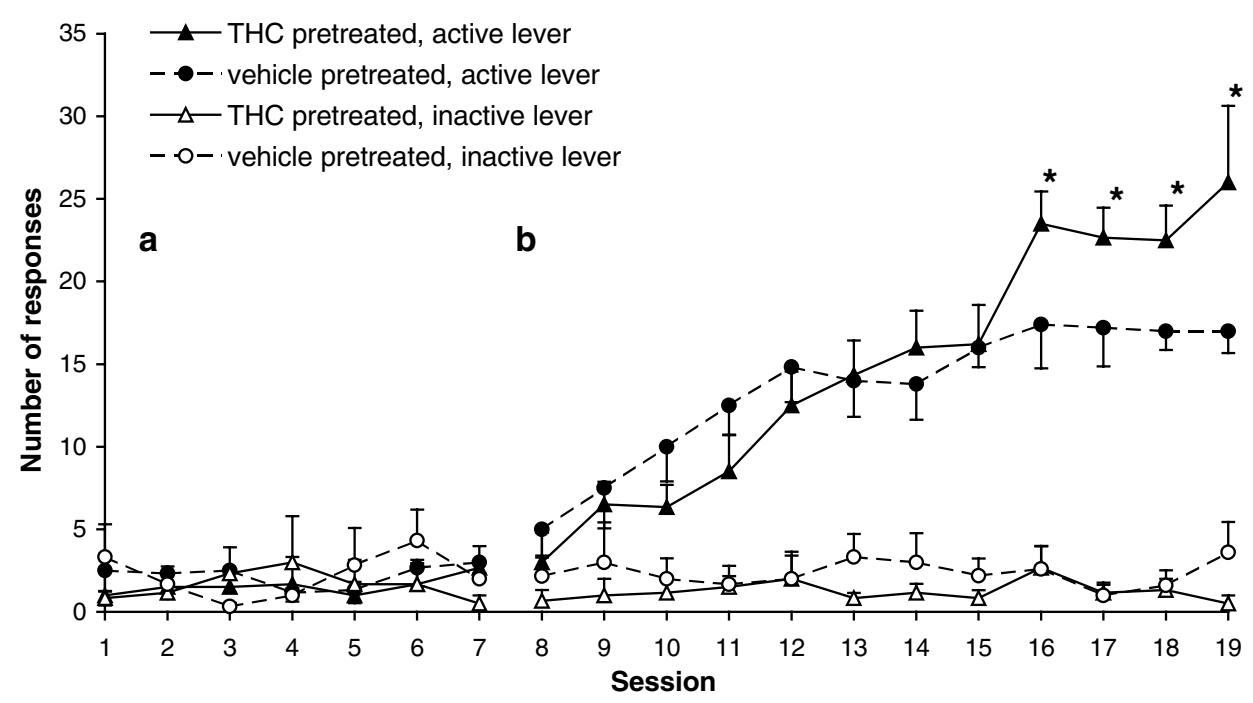

Figure I Heroin acquisition behavior on the active and inactive levers during (a) $15 \mu \mathrm{g} / \mathrm{kg} / \mathrm{infusion}$ and (b) $30 \mu \mathrm{g} / \mathrm{kg} / \mathrm{infusion}$ on an FR-I schedule of reinforcement in adult rats (beginning PND 57) following adolescent (PNDs 28-49) THC $(n=6)$ or vehicle $(n=5)$ exposure. * $p<0.05$ vs vehicle controls for each session. 


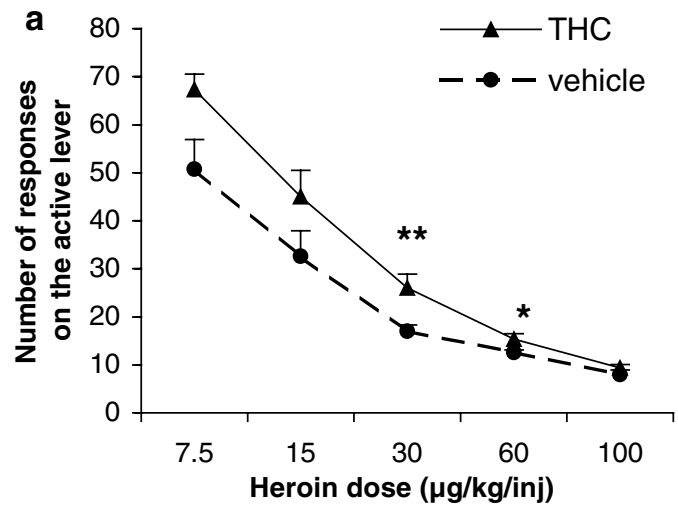

b

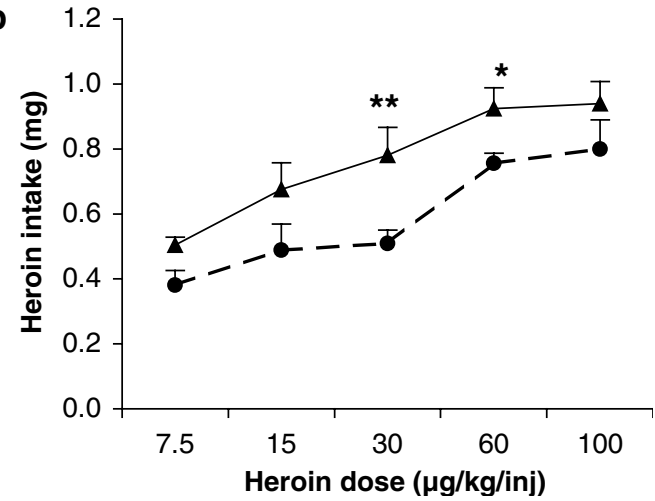

Figure 2 Between-session heroin self-administration behavior doseresponse curve $(7.5,15,30,60,100 \mu \mathrm{g} / \mathrm{kg} /$ infusion; randomized order) on an FR-I reinforcement schedule in rats pretreated with THC $(n=6)$ or vehicle $(n=5)$ during adolescence. (a) Responding for heroin (number of active lever presses) and (b) heroin intake $(\mathrm{mg})$ are shown as mean \pm SEM. ${ }^{*} p<0.05$; $* * 0.0$ I as compared to respective vehicle control.

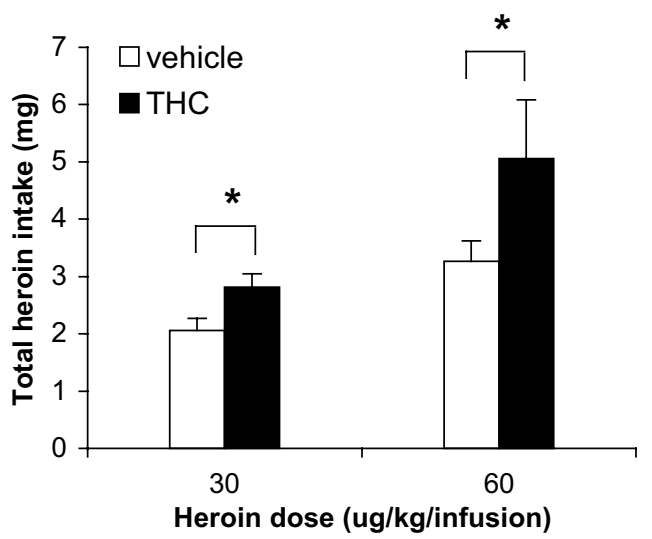

Figure 3 Total heroin intake over four consecutive sessions of stable response at 30 and $60 \mu \mathrm{g} / \mathrm{kg} /$ infusion in adult rats exposed to THC $(n=6)$ or vehicle $(n=5)$ during adolescence. ${ }^{*} p<0.05$ vs vehicle control.

$(\mathrm{F}(3,24)=7.74, p=0.0009)$ of the acute Rimonabant injection (Figure 4). Administration of $3.0 \mathrm{mg} / \mathrm{kg}$ Rimonabant reduced heroin intake as compared to baseline $(p<0.01)$ and to the other doses examined $(p<0.01)$.

Heroin-seeking behavior. Figure 5 shows the data obtained from the drug-seeking behavioral test using a paradigm where the number of responses on the active lever were

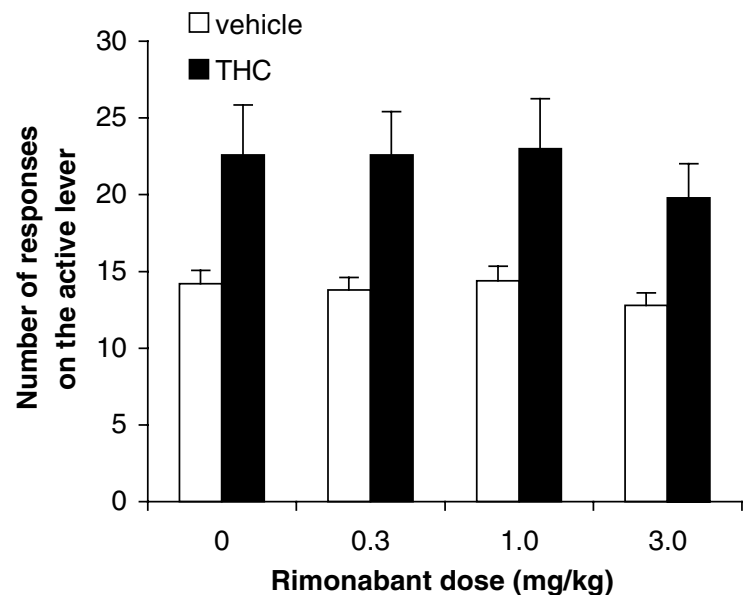

Figure 4 Effect of acute pretreatment with the cannabinoid antagonist Rimonabant (SR I4I7I6A) on heroin FR-I responding at $60 \mu \mathrm{g} / \mathrm{kg} /$ infusion in rats exposed to THC $(n=6)$ or vehicle $(n=5)$ during adolescence. Overall dose effect $(F(3,24)=7.74, p=0.0009)$. $p<0.01$ for $3 \mathrm{mg} / \mathrm{kg}$ vs baseline responding and all other doses tested.

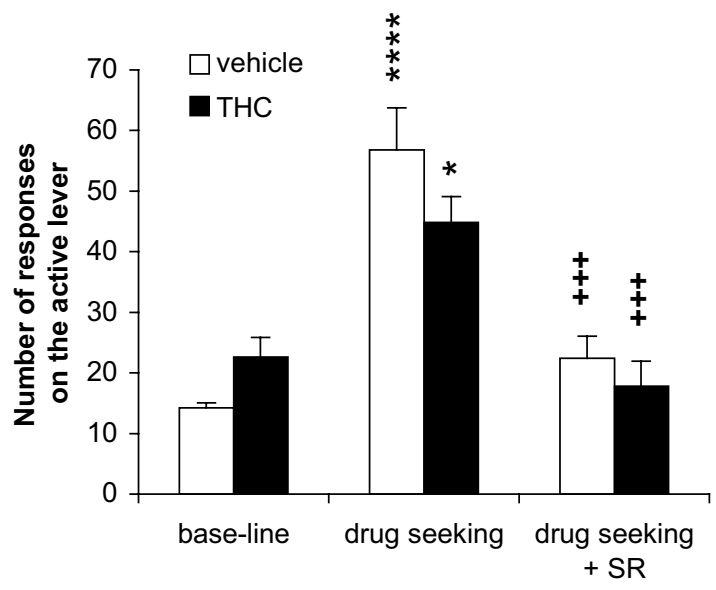

Figure 5 Heroin-seeking behavior (responding on the active lever in the absence of expected drug delivery; no cue light presentation) in THC$(n=5)$ or vehicle- $(n=5)$ exposed rats with and without acute Rimonabant pretreatment prior to the self-administration session. ${ }^{*} p<0.05$; ${ }^{* * * * * *} p<0.000$ I as compared to baseline. ${ }^{++}+p<0.00$ I vs drug-seeking paradigm without Rimonabant pretreatment.

counted but had no programmed consequences; no heroin was delivered during this session and no cue lights were presented. There was an overall significance of selfadministration paradigm $(\mathrm{F}(2,16)=45.31, p<0.000001)$ as well as paradigm $\times$ pretreatment interaction $(\mathrm{F}(2,16)=3.63$, $p<0.05)$. Post hoc Bonferroni corrections revealed a significant increase in the number of responses during the drug-seeking paradigm in both the vehicle- $(p<0.0001)$ and THC- $(p<0.05)$ exposed group. Vehicle-exposed animals had a higher percent increase than the THC-pretreated rats in the number of active lever responses $(328 \pm 58.3 v \mathrm{~s}$ $151 \pm 13.6 \% ; p<0.05)$; the vehicle group also had a higher number of inactive lever presses $(21.4 \pm 4.4$ vs $6.2 \pm 2.8$; $p<0.05)$. Rimonabant $(3.0 \mathrm{mg} / \mathrm{kg})$ administration before the drug-seeking session decreased the number of responses markedly in both the vehicle, $p<0.001)$ and THC $(p<0.001)$ subjects (Figure 5 ). There was, however, no difference 
between the pretreatment groups in the Rimonabantinduced behavioral effects.

\section{$\mathrm{CB}_{1}$ Receptor Density and Function}

Adolescent THC exposure did not significantly alter $\mathrm{CB}_{1}$ receptor or WIN 55,212-2-stimulated $\left[{ }^{35} \mathrm{~S}\right] \mathrm{GTP} \gamma \mathrm{S}$ binding in the brain areas studied at PND 57 when the behavioral studies were initiated in the other set of animals (Table 1), although there was a tendency toward increased $\left[{ }^{35} \mathrm{~S}\right] \mathrm{GTP} \gamma \mathrm{S}$ binding in the NAc core $(\mathrm{F}(1,9)=3.86, p=0.081)$ in THCpretreated rats. No significant difference was also observed between the THC- and vehicle-pretreated groups after heroin self-administration.

\section{$\mu \mathrm{OR}$ Density and Function}

Table 2 shows the analysis of $\left[{ }^{3} \mathrm{H}\right]$ DAMGO and DAMGOstimulated $\left[{ }^{35} \mathrm{~S}\right] \mathrm{GTP} \gamma \mathrm{S}$ binding prior to and after heroin self-administration for the striatum and substantia nigra; $\left.{ }^{3} \mathrm{H}\right]$ DAMGO binding in the VTA were below reliable detection limits. DAMGO-stimulated $\left[{ }^{35} \mathrm{~S}\right] \mathrm{GTP} \gamma \mathrm{S}$ binding was significantly increased in the substantia nigra $(\mathrm{F}(1,8)=9.23, \quad p<0.05)$ and the VTA $(\mathrm{F}(1,8)=7.34$, $p<0.05)$ in the THC-pre-exposed animals.

\section{Preproenkephalin mRNA Expression}

PENK, the propeptide precursor gene of the endogenous opioid enkephalin, was studied in the striatum; PENK mRNA is not expressed in the VTA or substantia nigra. Adolescent THC exposure was found to significantly increase PENK mRNA expression levels in the NAc shell $(\mathrm{F}(1,8)=17.21, p<0.01)$ of young adult rats (PND 57) (Figures 6 and 7). THC-exposed rats also expressed significantly higher levels of PENK mRNA expression in the NAc shell $(\mathrm{F}(1,5)=25.67, p<0.01)$ as compared to the vehicle-pretreated rats even after approximately 45 days of heroin self-administration.

\section{Correlation between Behavior and Neurochemical Measurements}

A significant correlation was found between the heroin selfadministration behavior (total number of active lever presses) exhibited on the last day of testing and the DAMGO-stimulated $\left[{ }^{35} \mathrm{~S}\right] \mathrm{GTP} \gamma \mathrm{S}$ binding measured in the NAc shell (Spearman's correlation $r=0.7563, p<0.05$ ). There was also a significant correlation between heroin intake behavior and the $\mathrm{CB}_{1}$ receptor binding in the substantia nigra $(r=0.7306, p<0.05)$. No other markers showed a significant correlation with the behavioral measures.

Table $2\left[{ }^{3} \mathrm{H}\right] \mathrm{DAMGO}$ - and $\left.{ }^{35} \mathrm{~S}\right] \mathrm{DAMGO}-\mathrm{Stimulated}$ GTP $\gamma \mathrm{S}$ Binding in Various Striatal and Brainstem Regions in Animals Exposed During Adolescence to THC or Vehicle

\begin{tabular}{|c|c|c|c|c|}
\hline & $\begin{array}{l}\text { Vehicle- } \\
\text { pretreated }\end{array}$ & $\begin{array}{c}\text { THC- } \\
\text { pretreated }\end{array}$ & $\begin{array}{l}\text { Vehicle- } \\
\text { heroin }\end{array}$ & $\begin{array}{l}\text { THC- } \\
\text { heroin }\end{array}$ \\
\hline \multicolumn{5}{|c|}{$\left[{ }^{3} \mathrm{H}\right] \mathrm{DAMGO}$ binding (c.p.m. $/ \mathrm{mm}^{2}$ ) } \\
\hline Caudate-putamen & $1.67 \pm 0.18$ & $2.14 \pm 0.25$ & $2.19 \pm 0.23$ & $1.98 \pm 0.27$ \\
\hline NAc core & $1.31 \pm 0.14$ & $1.60 \pm 0.16$ & $1.75 \pm 0.36$ & $1.84 \pm 0.16$ \\
\hline NAc shell & $1.19 \pm 0.16$ & $1.47 \pm 0.17$ & $1.70 \pm 0.26$ & $1.73 \pm 0.13$ \\
\hline Substantia nigra & $0.49 \pm 0.06$ & $0.52 \pm 0.05$ & $0.59 \pm 0.03$ & $0.85 \pm 0.09$ \\
\hline VTA & ND & ND & ND & ND \\
\hline \multicolumn{5}{|c|}{ DAMGO stimulated $\left[{ }^{35}\right.$ S]GTP $\mathrm{S}$ binding (\% change) } \\
\hline Caudate-putamen & $294 \pm 42$ & $265 \pm 22$ & $183 \pm 6$ & $223 \pm 38$ \\
\hline NAc core & $233 \pm 47$ & $254 \pm 34$ & $109 \pm 26$ & $147 \pm 29$ \\
\hline NAc shell & $438 \pm 58$ & $332 \pm 44$ & $217 \pm 19$ & $252 \pm 60$ \\
\hline Substantia nigra & $112 \pm 17$ & $219 \pm 26 *$ & $133 \pm 26$ & $|6| \pm 28$ \\
\hline VTA & $67 \pm 18$ & $147 \pm 2 \mid *$ & $108 \pm 15$ & $110 \pm 37$ \\
\hline
\end{tabular}

Animals were studied at postnatal day 57, a time period when heroin selfadministration was initiated in the behavioral study, and after approximately 45 days of heroin self-administration. Data are expressed as mean \pm SEM. * $p<0.05$ as compared to vehicle control; ND, not detectable.

Table I $\left[{ }^{3} \mathrm{H}\right] \mathrm{WIN55,212,2 \text {and } { } ^ { 3 5 } \mathrm { S } ] \mathrm { W } | \mathrm { N } 5 5 , 2 1 2 , 2 - S t i m u l a t e d} \mathrm{GTP} \gamma \mathrm{S}$ Binding in Various Striatal and Brainstem Regions in Animals Exposed during Adolescence to THC or Vehicle

\begin{tabular}{|c|c|c|c|c|}
\hline & Vehicle-pretreated & THC-pretreated & Vehicle-heroin & THC-heroin \\
\hline \multicolumn{5}{|c|}{$\left.{ }^{3} \mathrm{H}\right]$ WIN55,2 I 2 -2 binding $(\mu \mathrm{Ci} / \mathrm{g})$} \\
\hline Caudate-putamen & $0.069 \pm 0.023$ & $0.078 \pm 0.018$ & $0.067 \pm 0.016$ & $0.069 \pm 0.021$ \\
\hline NAc core & $0.084 \pm 0.039$ & $0.031 \pm 0.009$ & $0.079 \pm 0.013$ & $0.075 \pm 0.012$ \\
\hline NAc shell & $0.080 \pm 0.033$ & $0.027 \pm 0.019$ & $0.066 \pm 0.015$ & $0.099 \pm 0.054$ \\
\hline Substantia nigra & $0.840 \pm 0.142$ & $0.743 \pm 0.046$ & $1.029 \pm 0.108$ & $1.140 \pm 0.175$ \\
\hline \multicolumn{5}{|c|}{ WIN55,2 I 2 -2 stimulated $\left[{ }^{35}\right.$ S]GTP $\gamma$ S binding (\% change) } \\
\hline Caudate-putamen & $65 \pm 11$ & $71 \pm 14$ & $21 \pm 5$ & $32 \pm 8$ \\
\hline NAc core & $14 \pm 3$ & $38 \pm 14$ & $13 \pm 6$ & $22 \pm 9$ \\
\hline NAc shell & $25 \pm 6$ & $27 \pm 6$ & $19 \pm 6$ & $19 \pm 6$ \\
\hline
\end{tabular}

Animals were studied at postnatal day 57, a time period when heroin self-administration was initiated in the behavioral study, and after approximately 45 days of heroin self-administration. Data are expressed as mean \pm SEM. 


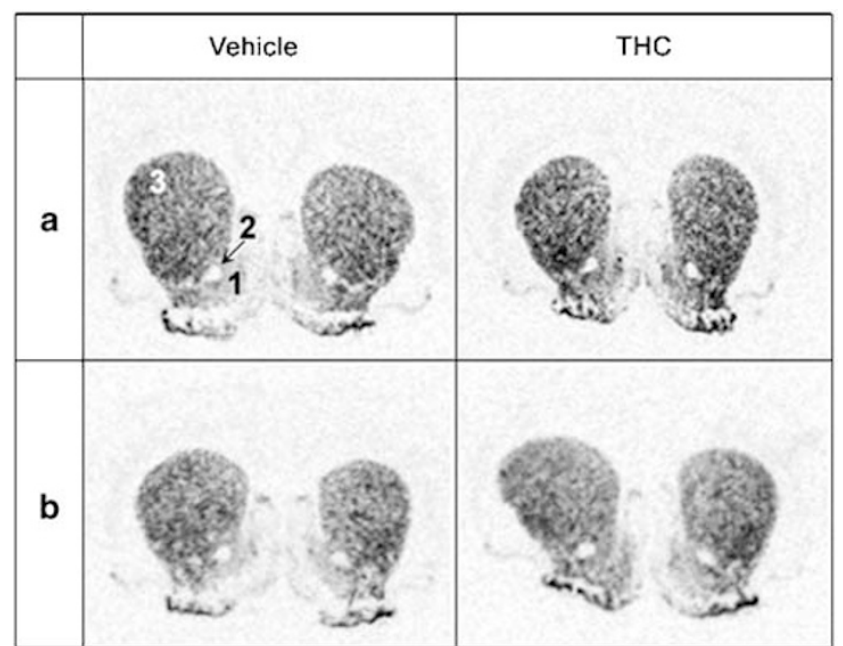

Figure $\mathbf{6}$ In situ hybridization autoradiograms showing the effects of adolescent exposure to $\mathrm{THC}$ or vehicle on preproenkephalin mRNA expression in the striatum of young adult rats (PND 57; a) and following 45 days of heroin self-administration at PND I02 (b; $n=4-6)$. I, NAc shell; 2 , NAc core; and 3, caudate-putamen.

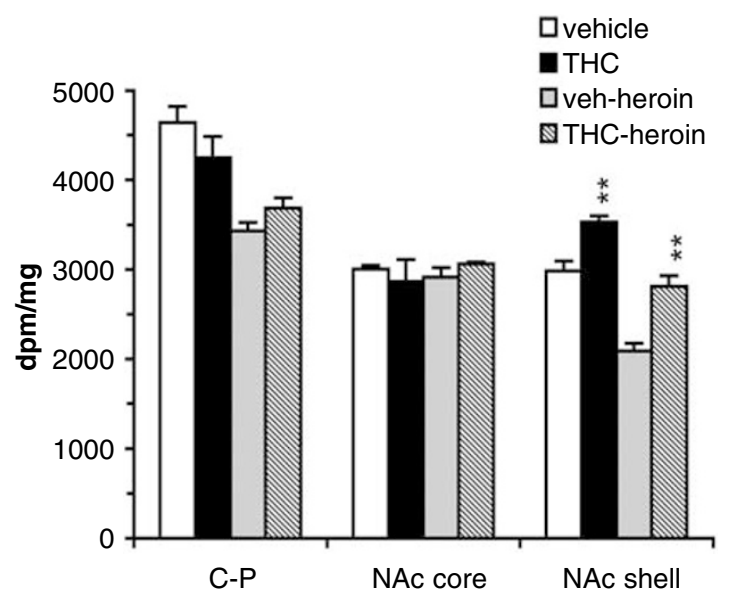

Figure 7 Proenkephalin mRNA expression levels (expressed as d.p.m./ mg; mean $\pm S E M)$ in the caudate-putamen $(C-P)$, nucleus accumbens (NAc) core, and NAc shell of adult rats with adolescent exposure to THC or vehicle. The data represent animals at the time point (PND 57) corresponding to the start of heroin self-administration and animals that had self-administered heroin for approximately 45 days $(n=4-6)$. *** $p<0.01$ as compared to respective vehicle control.

\section{DISCUSSION}

The present study provides evidence that adolescent exposure to THC increases opiate self-administration in adulthood and that this is associated with discrete alterations of the endogenous opioid system in limbic-related neuronal populations known to mediate reward behavior.

The periodic exposure to low-dose THC during adolescence did not appear to predispose animals to an increased sensitivity to initiate heroin self-administration. However, THC-pre-exposed subjects continued to shift their heroin intake upward during the acquisition period, whereas control animals maintained stable levels of drug selfadministration behavior. A significant impact of adolescent THC exposure continued to be evident even following acquisition given that THC animals (1) responded more for heroin at moderate to low doses and (2) had higher intake during the drug maintenance phase throughout the course of the experiment. The self-administration behavior demonstrated by the THC-pre-exposed animals would predict an enhanced risk for subsequent drug dependence considering that the switch from stable, controlled heroin intake to uncontrolled drug use that characterizes drug dependence is usually potentiated by increased heroin consumption over time (Ahmed et al, 2000).

It is difficult in rat models to discern the affective state of the animals and to establish definitively whether increased drug intake reflects increased drug liking/wanting (the FR-1 reinforcement schedule currently used does not dissociate drug 'liking' or 'wanting') or blunted reinforcement that could lead to compensated higher drug intake. Increased heroin intake on the descending limb of the dose-response curve (as the doses presently studied (Martin et al, 1998) has, however, been hypothesized to reflect a decrease in reward function (Ahmed and Koob, 2005). This allostatic hedonic hypothesis (Koob et al, 1997; Koob and Le Moal, 2001) would suggest that animals with adolescent THC exposure have an underlying hedonic deficit that is alleviated by increased heroin use. While this hypothesis is reasonable, it does not appear to fully account for why a hedonic deficit did not enhance initiation of heroin selfadministration behavior in the THC animals. It is possible that the potential hedonic deficit to the previous THC exposure is moderate and/or only becomes evident when the system is forced to adjust as, for example, during stress or repeated drug administration that requires self-regulatory control. The fact that THC-pre-exposed animals continued to shift their heroin intake to higher levels during the acquisition period would suggest different hedonic set points during early experience with heroin as compared to control animals. An alternate, although not mutually exclusive, hypothesis to a hedonic impairment in the THC-pretreated animals is that THC exposure increased the incentive motivation, that is, sensitization of craving (Robinson and Berridge, 2001), thereby leading to increased heroin intake. Our experiment showed that in the absence of heroin and associated cues, both THC and vehiclepretreated rats had similar elevated rates of responding on the active drug lever. Although the vehicle-exposed rats showed a higher percent increase in active responses than the THC rats, the behavior was not discriminative to the active lever since the control rats also had a higher increase in responding on the inactive lever. Using a progressive ratio self-administration paradigm, Solinas et al (2004a) showed that adult exposure to THC does not alter the incentive value of heroin even though the rats increased heroin intake. There may of course be differences in the incentive value of heroin in association with adolescent as compared to adult THC exposure, so altered motivation to self-administer the drug in a progressive ratio paradigm cannot be completely excluded.

The endogenous opioid neuropeptide most associated with regulating hedonic state is enkephalin (Skoubis et al, 2005), and the NAc (in particular the shell division) is the most limbic-related striatal subregion tightly coupled with reward behavior (Everitt and Wolf, 2002; Koob, 1992). The selective enhancement of PENK mRNA expression in the NAc shell could potentially underlie the altered heroin 
intake behavior evident in THC-exposed animals. The discrete THC-induced impairment of NAc PENK appears to be unique since alterations of the enkephalin system associated with repeated intake of other substances of abuse (Uhl et al, 1988) or highly rewarding food (Kelley et al, 2003) is normally widespread throughout the striatum. The apparent relative enhancement of NAc shell PENK gene expression in THC animals even after repeated opiate exposure, which generally decreases PENK transcription (Georges et al, 1999; Uhl et al, 1988), suggests a persistent disturbance of the enkephalin reward system with early THC exposure. Long-term disturbance of the PENK system appears a common feature of early THC exposure since we have recently observed a similar selective increased PENK mRNA expression in the NAc of adult offspring with THC exposure limited to the prenatal period; these animals also showed increased heroin intake (Spano et al, 2006). THC stimulates $\mathrm{CB}_{1}$ receptors, which similar to $\mu \mathrm{ORs}$, are coupled to Gi/o G-proteins (Pertwee and Ross, 2002) that should inhibit PENK transcription. Thus, increased PENK mRNA expression following the drug-free period into adulthood could reflect an allostatic response to counteract a potential downregulation of the PENK during THC exposure. There are still very few publications regarding THC effects on opioid neuropeptide transcription, especially in relation to drug exposure during development. Of these studies, Perez-Rosado et al (2000) did report reduced PENK mRNA expression during the prenatal period in THC-exposed fetuses, but this finding was only evident in the dorsal striatum. Time-course experiments following THC exposure are needed to validate the hypothesis that allostatic changes in PENK characterize distinct phases of THC exposure and related hedonic states.

In addition to selective disturbance of PENK, adolescent THC exposure was also associated with specific alteration of the $\mu \mathrm{OR}$ function. $\mu \mathrm{OR}$ coupling was significantly increased in the VTA and substantia nigra of the THC animals as young adults. Such alteration in the $\mu$ OR coupling would be expected to potentiate dopamine levels in forebrain areas such as the NAc and caudate-putamen, considering that stimulation of these midbrain receptors would disinhibit the inhibitory GABAergic regulation on dopamine cell firing (Johnson and North, 1992). The potential involvement of the dopamine system in regulating the long-term effects of THC should be directly addressed in future studies with the current animal model, but studies in the literature have already substantiated enhanced striatal dopamine levels following THC administration (Malone and Taylor, 1999; Tanda et al, 1997). Interestingly, heroin intake behavior was directly correlated with agonist activation of the $\mu$ OR GTP coupling and this observation was specifically localized to the NAc shell. These findings continue to substantiate an important role of the NAc $\mu \mathrm{OR}$ in heroin reinforcement.

There was no evidence of marked disruption of the $\mathrm{CB}_{1}$ receptor binding or coupling in the young adult rats with adolescent THC exposure in the current study, which is consistent with the observations that early alterations in $\mathrm{CB}_{1}$ receptor binding associated with repeated cannabinoid agonist administration generally normalize over time (Romero et al, 1998). There was, however, a significant positive correlation between the $\mathrm{CB}_{1}$ binding in the substantia nigra and heroin intake behavior. Increased
$\mathrm{CB}_{1}$ binding in this brainstem region would, similar to $\mu$ ORs described above, result in enhanced dopamine tone in the striatum. The correlation between the $\mathrm{CB}_{1}$ receptor and heroin self-administration underscores the significant functional interactions between the cannabinoid and opioid systems. In line with previous studies, we also confirmed an acute pharmacological regulation of cannabinoid receptor modulation of opiate self-administration behavior (Caille and Parsons, 2003; Navarro et al, 2001; Solinas et al, 2003). Blockade of the $\mathrm{CB}_{1}$ receptor with Rimonabant (at the $3 \mathrm{mg}$ / $\mathrm{kg}$ dose) inhibited heroin consumption, but there was no altered sensitivity in the THC-exposed rats, perhaps reflective of the lack of $\mathrm{CB}_{1}$ receptor alterations. Interestingly, the greatest effect of $\mathrm{CB}_{1}$ receptor blockade was with the attenuation of heroin-seeking behavior. These findings add to the growing evidence that Rimonabant could potentially serve as a treatment for heroin abuse where medication relevant for attenuating drug-seeking and relapse is of significant clinical value.

In summary, the current findings provide direct evidence in support of the gateway hypothesis that adolescent cannabis exposure contributes to greater heroin intake in adulthood. It is important to emphasize that our study does not exclude the contribution of other factors such as genetics, environment, and social issues that could influence the direct neurobiological effects of early THC exposure to either enhance or attenuate the progression to adult drug abuse. Systematic evaluation of these variables is needed to gain greater insight into apparent cannabis gateway effects on adult drug abuse vulnerability. Overall, the present study confirms a neurobiological convergence of the cannabinoid and opioid systems that is apparent on behavioral and molecular levels, suggesting altered hedonic processing in PENK and $\mu$ opioid limbic systems in association with enhanced heroin intake as a consequence of early THC exposure.

\section{ACKNOWLEDGEMENTS}

We thank Drs David Roberts and Sara Ward for valuable discussions and assistance in the self-administration behavioral model. This study was supported by the National Institutes of Health (NIDA DA19350).

\section{REFERENCES}

Agrawal A, Neale MC, Prescott CA, Kendler KS (2004). A twin study of early cannabis use and subsequent use and abuse/ dependence of other illicit drugs. Psychol Med 34: 1227-1237.

Ahmed SH, Koob GF (2005). Transition to drug addiction: a negative reinforcement model based on an allostatic decrease in reward function. Psychopharmacology (Berlin) 180: 473-490.

Ahmed SH, Walker JR, Koob GF (2000). Persistent increase in the motivation to take heroin in rats with a history of drug escalation. Neuropsychopharmacology 22: 413-421.

Andersen SL (2003). Trajectories of brain development: point of vulnerability or window of opportunity? Neurosci Biobehav Rev 27: 3-18.

Arseneault L, Cannon M, Poulton R, Murray R, Caspi A, Moffitt TE (2002). Cannabis use in adolescence and risk for adult psychosis: longitudinal prospective study. BMJ 325: 1212-1213.

Caille S, Parsons LH (2003). SR141716A reduces the reinforcing properties of heroin but not heroin-induced increases in nucleus accumbens dopamine in rats. Eur J Neurosci 18: 3145-3149. 
Charmandari E, Kino T, Souvatzoglou E, Chrousos GP (2003). Pediatric stress: hormonal mediators and human development. Horm Res 59: 161-179.

Cossu G, Ledent C, Fattore L, Imperato A, Bohme GA, Parmentier $M$ et al (2001). Cannabinoid CB1 receptor knockout mice fail to self-administer morphine but not other drugs of abuse. Behav Brain Res 118: 61-65.

Everitt BJ, Wolf ME (2002). Psychomotor stimulant addiction: a neural systems perspective. J Neurosci 22: 3312-3320.

Fergusson DM, Horwood LJ (2000). Does cannabis use encourage other forms of illicit drug use? Addiction 95: 505-520.

Fergusson DM, Horwood LJ, Swain-Campbell NR (2003). Cannabis dependence and psychotic symptoms in young people. Psychol Med 33: 15-21.

Georges F, Stinus L, Bloch B, Le Moine C (1999). Chronic morphine exposure and spontaneous withdrawal are associated with modifications of dopamine receptor and neuropeptide gene expression in the rat striatum. Eur J Neurosci 11: 481-490.

Green AI, Tohen MF, Hamer RM, Strakowski SM, Lieberman JA, Glick I et al (2004). First episode schizophrenia-related psychosis and substance use disorders: acute response to olanzapine and haloperidol. Schizophr Res 66: 125-135.

Hall WD, Lynskey M (2005). Is cannabis a gateway drug? Testing hypothesis about the relationship between cannabis and the use of other illicit drugs. Drug Alcohol Rev 24: 39-48.

Hibell B, Andersson B, Bjarnason T, Ahlström S, Balakireva O, Kokkevi A et al (2004). The ESPAD Report 2003. Alcohol and Other Drug Use Among Students in 35 European Countries. The ESPAD Report 2003. Alcohol and Other Drug Use Among Students in 35 European Countries. The Swedish Council for Information on Alcohol and Other Drugs (CAN) and the Pompidou Group at the Council of Europe. Stockholm, Sweden.

Hurd YL, Suzuki M, Sedvall GC (2001). D1 and D2 dopamine receptor mRNA expression in whole hemisphere sections of the human brain. J Chem Neuroanat 22: 127-137.

Johnson S, North R (1992). Opioids excite dopamine neurons by hyperpolarization of local interneurons. J Neurosci 12: 483-488.

Kelley AE, Will MJ, Steininger TL, Zhang M, Haber SN (2003). Restricted daily consumption of a highly palatable food (chocolate Ensure $(\mathrm{R})$ ) alters striatal enkephalin gene expression. Eur J Neurosci 18: 2592-2598.

Koob GF (1992). Neural mechanisms of drug reinforcement. Ann NY Acad Sci 654: 171-191.

Koob GF, Caine SB, Parsons L, Markou A, Weiss F (1997). Opponent process model and psychostimulant addiction. Pharm Biochem Beh 57: 513-521.

Koob GF, Le Moal M (2001). Drug addiction, dysregulation of reward, and allostasis. Neuropsychopharmacology 24: 97-129.

Ledent C, Valverde O, Cossu G, Petitet F, Aubert JF, Beslot F et al (1999). Unresponsiveness to cannabinoids and reduced addictive effects of opiates in CB1 receptor knockout mice. Science 283: 401-404.

Lynskey MT, Heath AC, Bucholz KK, Slutske WS, Madden PA, Nelson EC et al (2003). Escalation of drug use in early-onset cannabis users vs co-twin controls. JAMA 289: 427-433.

MacCoun R (1998). In what sense (if any) is marijuana a gateway drug? FAS Drug Policy Anal Bull, URL: http://www.fas.org/drugs/ issue4.htmgateway

Malone DT, Taylor DA (1999). Modulation by fluoxetine of striatal dopamine release following Delta9-tetrahydrocannabinol: a microdialysis study in conscious rats. Br J Pharmacol 128: 21-26.

Martin TJ, Smith JE, Dworkin SI (1998). Training dose and session time as contextual determinants of heroin self-administration in rats. Pharmacol Biochem Behav 60: 415-421.

Navarro M, Carrera MR, Fratta W, Valverde O, Cossu G, Fattore L et al (2001). Functional interaction between opioid and cannabinoid receptors in drug self-administration. J Neurosci 21: $5344-5350$.
Paxinos G, Watson C (1997). The Rat Brain in Stereotaxic Coordinates. The Rat Brain in Stereotaxic Coordinates. Academic Press: New York.

Perez-Rosado A, Manzanares J, Fernandez-Ruiz J, Ramos JA (2000). Prenatal Delta(9)-tetrahydrocannabinol exposure modifies proenkephalin gene expression in the fetal rat brain: sexdependent differences. Brain Res Dev Brain Res 120: 77-81.

Pertwee RG, Ross RA (2002). Cannabinoid receptors and their ligands. Prostaglandins Leukot Essent Fatty Acids 66: 101-121.

Pickel VM, Chan J, Kash TL, Rodriguez JJ, MacKie K (2004). Compartment-specific localization of cannabinoid 1 (CB1) and mu-opioid receptors in rat nucleus accumbens. Neuroscience 127: 101-112.

Rice D, Barone Jr S (2000). Critical periods of vulnerability for the developing nervous system: evidence from humans and animal models. Environ Health Perspect 108(Suppl 3): 511-533.

Robinson TE, Berridge KC (2001). Incentive-sensitization and addiction. Addiction 96: 103-114.

Rodriguez JJ, Mackie K, Pickel VM (2001). Ultrastructural localization of the CB1 cannabinoid receptor in mu-opioid receptor patches of the rat caudate-putamen nucleus. J Neurosci 21: 823-833.

Romero J, Berrendero F, Manzanares J, Perez A, Corchero J, Fuentes JA et al (1998). Time-course of the cannabinoid receptor down-regulation in the adult rat brain caused by repeated exposure to delta9-tetrahydrocannabinol. Synapse 30: 298-308.

SAMHSA (2004). Substance Abuse and Mental Health Service Administration. Results from the 2003 National Survey on Drug Use and Health: National Findings, Office of Applied Studies, NSDUH Series H-25. DHHS: Rockville, MD.

Skoubis PD, Lam HA, Shoblock J, Narayanan S, Maidment NT (2005). Endogenous enkephalins, not endorphins, modulate basal hedonic state in mice. Eur J Neurosci 21: 1379-1384.

Solinas M, Panlilio LV, Antoniou K, Pappas LA, Goldberg SR (2003). The cannabinoid CB1 antagonist $N$-piperidinyl-5-(4chlorophenyl)-1-(2, 4-dichlorophenyl)-4-methylpyrazole-3-carboxamide $(S R-141716 \mathrm{~A})$ differentially alters the reinforcing effects of heroin under continuous reinforcement, fixed ratio, and progressive ratio schedules of drug self-administration in rats. J Pharmacol Exp Ther 306: 93-102.

Solinas M, Panlilio LV, Goldberg SR (2004a). Exposure to delta-9tetrahydrocannabinol (THC) increases subsequent heroin taking but not heroin's reinforcing efficacy: a self-administration study in rats. Neuropsychopharmacology 29: 1301-1311.

Solinas M, Zangen A, Thiriet N, Goldberg SR (2004b). Betaendorphin elevations in the ventral tegmental area regulate the discriminative effects of Delta-9-tetrahydrocannabinol. Eur J Neurosci 19: 3183-3192.

Spano SM, Ellgren M, Wang X, Hurd YL (2006). Prenatal cannabis exposure increases heroin seeking with allostatic changes in limbic enkephalin systems in adulthood. Biol Psych (in press).

Spear LP (2000). The adolescent brain and age-related behavioral manifestations. Neurosci Biobehav Rev 24: 417-463.

Tanda G, Pontieri FE, Di Chiara G (1997). Cannabinoid and heroin activation of mesolimbic dopamine transmission by a common mul opioid receptor mechanism. Science 276: 2048-2050.

Uhl GR, Ryan JP, Schwartz JP (1988). Morphine alters preproenkephalin gene expression. Brain Res 459: 391-397.

van Os J, Bak M, Hanssen M, Bijl RV, de Graaf R, Verdoux H (2002). Cannabis use and psychosis: a longitudinal populationbased study. Am J Epidemiol 156: 319-327.

Veen ND, Selten JP, van der Tweel I, Feller WG, Hoek HW, Kahn RS (2004). Cannabis use and age at onset of schizophrenia. Am J Psychiatry 161: 501-506.

Yamaguchi K, Kandel DB (1984). Patterns of drug use from adolescence to young adulthood: III. Predictors of progression. Am J Public Health 74: 673-681. 